\title{
Correlation between Age and Electrical Axes of the Heart in Adult Nigerians
}

\author{
Peter Ekpunobi Chime ${ }^{1 *}$, Wilfred Okwudili Okenwa ${ }^{2}$, Bibiana Oti ${ }^{1}$ \\ ${ }^{1}$ Department of Medicine, Enugu State University of Science and Technology Teaching Hospital, Parklane, Enugu, Nigeria \\ ${ }^{2}$ Department of Surgery, Enugu State University of Science and Technology Teaching Hospital, Parklane, Enugu, Nigeria \\ Email: *pe4chyme@yahoo.com
}

How to cite this paper: Chime, P.E. Okenwa, W.O. and Oti, B. (2020) Correlation between Age and Electrical Axes of the Heart in Adult Nigerians. World Journal of Cardiovascular Diseases, 10, 761-768. https://doi.org/10.4236/wjcd.2020.1011072

Received: August 21, 2020

Accepted: November 13, 2020

Published: November 16, 2020

Copyright $\odot 2020$ by author(s) and Scientific Research Publishing Inc. This work is licensed under the Creative Commons Attribution International License (CC BY 4.0).

http://creativecommons.org/licenses/by/4.0/

\begin{abstract}
Background: P wave axis, QRS axis, T wave axis and QRS-T angle have prognostic values on cardiovascular morbidity and mortality, yet the effect of age on these important electrocardiographic parameters has not been well studied in adult Nigerians, knowing that some electrocardiographic parameters are affected by age. Objectives: This study was aimed at determining the effect of age on P frontal axis, QRS frontal axis, T frontal axis and frontal QRS-T angle among adult Nigerians. Methods: This was a retrospective study in which $\mathrm{P}$ frontal axis, QRS frontal axis and $\mathrm{T}$ frontal axis of adult patients who attended a university teaching hospital were determined from 12-lead ECG. Frontal QRS-T angle was calculated as the absolute difference between the QRS frontal axis and T wave frontal axis. The electrical axes and QRS-T angle were correlated with age. Results: There were 85 cases aged between 20 and 66 years, which included 42 males and 43 females. P frontal axis correlated positively and non-significantly with age $(\mathrm{r}=-0.032, \mathrm{p}=0.773)$, $\mathrm{QRS}$ frontal axis correlated negatively and significantly with age $(r=-0.295, p=0.006), T$ frontal axis correlated negatively and non-significantly with age $(r=-0.002, p$ $=0.984$ ), while frontal QRS-T angle correlated negatively and significantly with age $(r=-0.266, p=0.014)$. Conclusion: There were significant age related changes in both QRS frontal axis and frontal QRS-T angle. No significant age related changes were found in $\mathrm{P}$ frontal axis and $\mathrm{T}$ frontal axis.
\end{abstract}

\section{Keywords}

P Frontal Axis, T Frontal Axis, QRS Frontal axis, Frontal QRS-T Angle

\section{Introduction}

The commonly recorded electrical axes of the heart on the 12-lead surface elec-

${ }^{*}$ Corresponding author. 
trocardiogram (ECG) are $\mathrm{P}$ wave axis, $\mathrm{QRS}$ axis and $\mathrm{T}$ wave axis. The prognostic value of abnormal $\mathrm{P}$ wave axis in cardiovascular morbidity and mortality [1] [2], has been demonstrated in previous studies. $\mathrm{T}$ wave axis has also been shown to be a strong predictor of cardiac morbidity, cardiac mortality and all-cause mortality [3] [4] [5] [6]. QRS-T angle, which is the angle between QRS axis and T wave axis, is a strong predictor of cardiac morbidity, cardiac mortality and all-cause mortality [4] [7] [8]. Since QRS-T angle is the difference between the QRS axis and T wave axis [9] QRS-T angle indirectly indicates the prognostic value of QRS axis. Despite their clinical importance, the effect of age on these electrocardiographic parameters has not been well studied among adult Nigerians, given that some electrocardiographic parameters are affected by age. This study was aimed at determining the effect of age on P frontal axis, QRS frontal axis, $\mathrm{T}$ frontal axis and frontal QRS-T angle, among adult Nigerians.

Reference values for $\mathrm{P}$ wave axis, QRS-axis, T-wave axis and QRS-T angle are available in the literature. The reference range for $\mathrm{P}$ wave axis is 0 to 75 degrees [1]. The reference range for QRS-axis is -30 to 90 degrees [4], for T-wave axis is 0 to 90 degrees [4] and for frontal QRS-T angle is 0 to 90 degrees [4]. Frontal QRS-T angle is usually smaller than the corresponding spatial QRS-T angle [10] [11].

Chaudhry et al. [12] reported no significant change in $\mathrm{P}$ axis with increasing age in adults. Chaudhry et al. also reported that QRS axis decreased significantly with age while $\mathrm{T}$ axis increased significantly with age. QRS-T angle was reported by Oehler et al. [9] and by Chaudhry et al. [12] to increase with age.

Even though such studies have been done in Caucasians, findings in Caucasians and other races regarding the relationship between age and electrical axes of the heart may not be assumed to be applicable to Nigerians because racial variations in some ECG parameters are known to exist [13] [14]. This necessitated the examination of this problem in adult Nigerians.

\section{Materials and Methods}

\subsection{Data Acquisition}

This was a retrospective study. Eligible cases that attended the medical outpatient clinics of Enugu State University Teaching Hospital, (ESUTH) Parklane, Enugu, Nigeria, between February and July 2016 were recruited retrospectively and consecutively. The medical outpatient register was used for the initial screening of cases to be or not to be included in the study. Those included were adults 18 years of age and above and those excluded were those with history of heart disease, kidney disease, obesity, chronic obstructive pulmonary disease and pregnant females. Many were excluded based on the information from the outpatient register alone. The medical records of those who were through in the initial screening were then examined for further evidence of the exclusion criteria. In the end, 85 cases met the requirement for eligibility.

$\mathrm{P}$ frontal axis, QRS frontal axis and $\mathrm{T}$ frontal axis were determined from the 
ECG.

\subsection{Data Analysis}

Frontal QRS-T angle (QTA) was calculated as the absolute difference between QRS frontal axis and T frontal axis [7] [15].

$$
\mathrm{QTA}=\mathrm{QRS} \text { axis }-\mathrm{T} \text { wave axis }
$$

where QTA is QRS-T angle.

This is for QRS-T angle not greater than 180 degrees [9].

Where QRS axis - T wave axis $>180$ degrees, the following formula was used to calculate QRS-T angle [7] [9].

$$
\mathrm{QRS}-\mathrm{T} \text { angle }=360-(\mathrm{QRS} \text { axis }-\mathrm{T} \text { wave axis })
$$

Analysis of data was with statistical product and service solutions (SPSS) software version 22 (IBM Statistics, IBM Corp). Group means were compared using analysis of variance (ANOVA). Bivariate correlation was employed in examining the relationship between age and electrographic parameters. $\mathrm{P}$ values less than 0.05 were considered significant.

\section{Results}

\subsection{Distribution of the Electrical Axes of the Heart across the Different Age Groups}

Data on 85 cases aged between 20 and 66 years with a mean age of $44.61 \pm 10.04$ were analyzed. They included 42 males and 43 females.

The distribution of mean $\mathrm{P}$ frontal axis across the different age groups followed no definite pattern. Across the third decade, fourth decade, fifth decade, sixth decade and seventh decade of life, the distribution of mean $P$ frontal axis in degrees was $48.71 \pm 21.12,49.33 \pm 18.20,47.08 \pm 20.18,50.45 \pm 23.91$ and 51.40 \pm 25.63 , respectively. See Table 1 . The overall mean P frontal axis was $48.54 \pm$ 20.08 .

\begin{tabular}{|c|c|c|c|c|c|c|c|}
\hline & $\begin{array}{c}3^{\text {rd }} \text { decade } \\
N=7\end{array}$ & $\begin{array}{c}4^{\text {th }} \text { decade } \\
n=24\end{array}$ & $\begin{array}{c}5^{\text {th }} \text { decade } \\
N=38\end{array}$ & $\begin{array}{c}6^{\text {th }} \text { decade } \\
N=11\end{array}$ & $\begin{array}{c}7^{\text {th }} \text { decade } \\
N=5\end{array}$ & $\begin{array}{c}\text { Total } \\
\mathrm{N}=85\end{array}$ & $P$ value \\
\hline Age & $22.86 \pm 1.95$ & $37.67 \pm 1.27$ & $46.82 \pm 1.71$ & $57.27 \pm 1.49$ & $63.80 \pm 1.79$ & $44.61 \pm 10.04$ & 0.000 \\
\hline$P$ axis & $48.71 \pm 21.12$ & $49.33 \pm 18.20$ & $47.08 \pm 20.18$ & $50.45 \pm 23.91$ & $51.40 \pm 25.63$ & $48.54 \pm 20.08$ & 0.980 \\
\hline QRS axis & $50.57 \pm 22.10$ & $44.13 \pm 21.69$ & $35.32 \pm 19.68$ & $29.82 \pm 20.05$ & $24.20 \pm 18.32$ & $37.69 \pm 21.10$ & 0.059 \\
\hline $\mathrm{T}$ axis & $34.71 \pm 21.91$ & $31.33 \pm 19.76$ & $28.66 \pm 18.15$ & $30.64 \pm 20.35$ & $32.80 \pm 23.42$ & $30.41 \pm 19.11$ & 0.940 \\
\hline QTA & $15.86 \pm 24.71$ & $12.79 \pm 22.04$ & $6.66 \pm 23.41$ & $-0.82 \pm 24.86$ & $-8.60 \pm 15.18$ & $7.28 \pm 23.26$ & 0.200 \\
\hline
\end{tabular}

Table 1. The mean frontal electrical axes of the different age groups.

Key: QTA means QRS-T angle. 
Starting from the third decade where the mean QRS frontal axis was $50.57 \pm$ 22.10 , it decreased progressively through the fourth decade $(44.13 \pm 21.69)$, fifth decade $(35.32 \pm 19.68)$, sixth decade $(29.82 \pm 20.05)$ to the seventh decade of life $(24.20 \pm 18.32)$. The overall mean QRS frontal axis was $37.69 \pm 21.10$. See Table 1 .

The $\mathrm{T}$ frontal axis had no definite pattern across the different age groups. In degrees, it was $34.71 \pm 21.91$ in the third decade, $31.33 \pm 19.76$ in the fourth decade, $28.66 \pm 18.15$ in the fifth decade, $30.64 \pm 20.35$ in the sixth decade and $32.80 \pm 23.42$ in the seventh decade of life. The overall mean $\mathrm{T}$ frontal axis was $30.41 \pm 19.11$. See Table 1 .

The mean frontal QRS-T angle decreased from $15.86 \pm 24.71$ in the third decade to $12.79 \pm 22.04$ in the fourth decade, to $6.66 \pm 23.41$ in the fifth decade, and thereafter increased negatively from $-0.82 \pm 24.86$ in the sixth decade to $-8.60 \pm$ 15.18 in the seventh decade of life. The overall mean QRS-T angle was 7.28 \pm 23.26. See Table 1. From Figure 1 it can be seen that with increasing age, QRS frontal axis moves superiorly (i.e., in anti-clockwise direction) in the frontal plane. The intersection of the QRS frontal axis and $\mathrm{T}$ wave frontal axis was at about 58 years.

\subsection{Correlation between the Electrical Axes of the Heart and Age}

$\mathrm{P}$ frontal axis correlated positively and non-significantly with age $(\mathrm{r}=-0.032, \mathrm{p}$ $=0.773)$, QRS frontal axis correlated negatively and significantly with age $(\mathrm{r}=$ $-0.295, \mathrm{p}=0.006)$, $\mathrm{T}$ frontal axis correlated negatively and non-significantly with age $(\mathrm{r}=-0.002, \mathrm{p}=0.984)$ while frontal QRS-T angle correlated negatively and significantly with age $(r=-0.266, \mathrm{p}=0.014)$. See Table 2 .

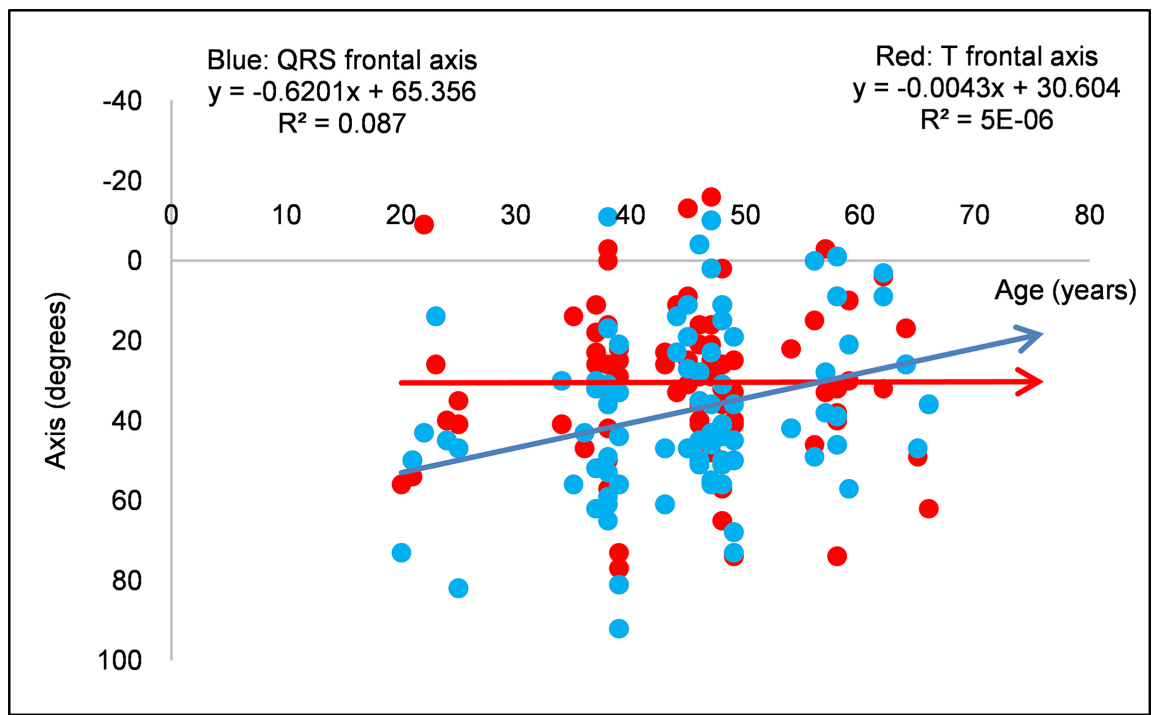

Figure 1. Graphs of QRS frontal axis and T frontal axis extrapolated forward by 10 years. The $y$-axis is in reverse order in order to portray the orientation of the QRS axis and T wave axis in the frontal plane. With increasing age, QRS frontal axis moves superiorly or anti-clockwise in the frontal plane. 
Table 2. Correlation of frontal axes with age.

\begin{tabular}{ccccc}
\hline & P axis & QRS axis & T axis & QTA \\
\hline $\begin{array}{c}\text { Mean } \pm \text { SD } \\
\text { (degrees) }\end{array}$ & $48.54 \pm 20.08$ & $37.69 \pm 21.10$ & $30.41 \pm 19.11$ & $7.28 \pm 23.26$ \\
$\begin{array}{c}\text { Pearson's regression } \\
\text { coefficient (r) }\end{array}$ & 0.032 & -0.295 & -0.002 & -0.266 \\
P value & 0.773 & 0.006 & 0.984 & 0.014 \\
\hline
\end{tabular}

Key: QTA means QRS-T angle.

\section{Discussion}

$\mathrm{P}$ wave axis, $\mathrm{T}$ wave axis and QRS-T angle have prognostic values on cardiovascular morbidity and mortality and so it was considered necessary to determine the effect of age on these important ECG parameters. To the best of our knowledge, no previous studies had examined the decade to decade changes in the frontal QRS-T angle among adult Nigerians. This study analyzed the decade to decade changes in the commonly determined electrical axes of the heart and also the decade to decade changes in the frontal QRS-T angle.

There was no definite pattern in the distribution of $\mathrm{P}$ frontal axis from the third decade to the seventh decade of life. The correlation between $\mathrm{P}$ frontal axis and age was very poor. Just like in our own study, Chaudhry et al. [12] found no significant change in $\mathrm{P}$ axis with increasing age among the adults they studied. Also, Parhels et al. [10] reported that $\mathrm{P}$ frontal axis does not change with age throughout adult life.

In the case of QRS frontal axis, there was a progressive decrease across the third decade, fourth decade, fifth decade, sixth decade and seventh decade of life. QRS frontal axis correlated negatively and significantly with age. The findings in our study corroborated those of Chaudhry et al. [12] and Parhels et al. [10] who reported that QRS frontal axis decreased with increasing age.

Just like $\mathrm{P}$ frontal axis, the correlation between $\mathrm{T}$ frontal axis and age was poor in our study. This is contrary to what Chaudhry et al. [12] found in their own study in which the $\mathrm{T}$ frontal axis was found to increase with age. However, Parhels et al. [10] in their own study, reported that $\mathrm{T}$ frontal axis moves superiorly (i.e., decreases) after which it moves inferiorly (i.e., increases).

In our study, the frontal QRS-T angle decreased from the third decade to the fifth decade and thereafter increased negatively from the sixth decade to the seventh decade of life. This was due to the superior or anticlockwise movement of the QRS frontal axis in the frontal plane with increasing age (Figure 1). Although Stinebaugh et al. [16] found no significant change in the QRS-T among adults, Oehler et al. and Chaudhry et al. reported that QRS-T angle increased with age. In our study of adult subjects aged between 20 and 66 years, the mean frontal QRS-T angle in degrees was 7.28 \pm 23.26. This was comparable to those of Parhels et al. [10] who reported a mean frontal QRS-T angle of $4.1 \pm 32.4$ 
among adult subjects aged between 18 and 64 years. In the same study by Parhels et al., adult subjects aged between 65 and 88 years were reported to have a mean frontal QRS-T angle of $22.7+36.8$. This second group included those in the eighth and ninth decades of life. Our study did not include those in the eighth and ninth decades of life.

It is obvious from our study and those of Parhels et al. that frontal QRS-T angle has a relatively small mean as well as a relatively narrow range. This was well illustrated in the study by Draper et al. [11] in which frontal QRS-T angle, sagittal QRS-T angle, horizontal QRS-T angle and spatial QRS-T angle were compared in the same subjects. Of the four, the mean frontal QRS-T angle was the least. The mean frontal QRS-T angle in degrees was $12 \pm 33$, while the corresponding spatial QRS-T angle in the same subjects was $78 \pm 26$. The range of the frontal QRS-T angle in degrees was $0-88$, while the corresponding range of the spatial QRS-T angle in degrees was $26-134$.

\section{Conclusion}

This study on young adult and middle-aged Nigerians showed significant changes in QRS frontal axis and QRS-T angle with respect to age, similar to what were reported in previous studies among non-Negro populations. The absence of age related changes in P frontal axis in adult Nigerians was also similar to what was reported among non-Negro populations. The mean QRS-T angle recorded in the age group studied was small and in agreement with the observation made by previous researchers.

\section{The Strength of the Study}

The cases studied were those who had no clinical evidence of heart disease.

\section{The Limitation of the Study}

We acknowledged the small scale of the study with regards to sample size, especially in the seventh decade where there were only five cases. When recruiting the cases for the study, it was considered important to select only those cases which did not have heart disease, or any disease that might affect cardiac electrophysiology, in other to limit the confounding factors.

\section{Recommendation}

Given the prognostic importance of $\mathrm{P}$ wave axis, $\mathrm{T}$ wave axis and QRS-T angle on cardiovascular morbidity and mortality, and also given that these electrocardiographic parameters are affected by age, electrocardiographic screening of adults and the elderly before any physically stressful condition such as strenuous exercise or surgery should warrant serious consideration.

For future studies on the effect of age on the electrical axes of the heart, we recommend a large scale study that will include elderly Nigerians in order to understand the age-related changes in the electrical axes of the heart of the el- 
derly Nigerians.

\section{Conflicts of Interest}

The authors declare no conflicts of interest regarding the publication of this paper.

\section{References}

[1] Maheshwari, A., Norby, F.L., Soliman, E.Z., et al. (2017) Abnormal P-Wave Axis and Ischemic Stroke. The ARIC Study (Atherosclerosis Risk in Communities). Stroke, 48, 2060-2065. https://doi.org/10.1161/STROKEAHA.117.017226

[2] Li, Y., Shah, A.J. and Soliman, E.Z. (2014) Effect of Electrocardiographic P-Wave Axis on Mortality (ABSTRACT). The American Journal of Cardiology, 113 372-376. https://doi.org/10.1016/j.amjcard.2013.08.050

[3] Salles, G.F., Xavier, S.S. and Sousa, A.S., Hasslocher-Moreno, A. and Cardoso, C.R.L. (2004) T-Wave Axis Deviation as an Independent Predictor of Mortality in Chronic Chagas' Disease. The American Journal of Cardiology, 93, 1136-1140. https://doi.org/10.1016/j.amjcard.2004.01.040

[4] Aro, A.L., Huikuri, H.V., Tikkanen, J.T., Junttila, M.J., Rissanen, H.A., Reunanen, A. and Anttonen, O. (2012) QRS-T Angle as a Predictor of Sudden Cardiac Death in a Middle-Aged General Population. EP Europace, 14, 872-876.

https://doi.org/10.1093/europace/eur393

[5] Kors, J.A., de Bruyne, M.C., Hoes, A.W., van Herpen, G., Hofman, A., et al. (1998) T-Axis as an Indicator of Risk of Cardiac Events in Elderly People. Lancet, 352, 601-605. tps://doi.org/10.1016/S0140-6736(97)10190-8

[6] Rautaharju, P.M., Nelson, J.C., Kronmal, R.A., Zhang, Z.M., Robbins, J., Gottdiener, J.S., et al. (2001) Usefulness of T-Axis Deviation as an Independent Risk Indicator for Incident Cardiac Events in Older Men and Women Free from Coronary Heart Disease (the Cardiovascular Health Study). The American Journal of Cardiology, 88, 118-123. https://doi.org/10.1016/S0002-9149(01)01604-6

[7] Zhang, Z.M., Prineas, R.J., Case, D., Soliman, E.Z., Rautaharju, P.M. and ARIC Research Group (2007) Comparison of the Prognostic Significance of the electrocardiographic QRS/T Angles in Predicting Incident Coronary Heart Disease and Total Mortality (from the Atherosclerosis Risk in Communities Study). The American Journal of Cardiology, 100, 844-849. https://doi.org/10.1016/j.amjcard.2007.03.104

[8] Skampardoni, S., Green, D., Hnatkova, K., Malik, M., Kalra, P.A. and Poulikakos, D. (2019) QRS-T Angle Predicts Cardiac Risk and Correlates with Global Longitudinal Strain in Prevalent Hemodialysis Patients. Frontiers in Physiology, 10, 145. https://doi.org/10.3389/fphys.2019.00145

[9] Oehler, A., Feldman, T., Henrikson, C.A. and Tereshchenko, L.G. (2014) QRS-T Angle: A Review. Annals of Noninvasive Electrocardiology, 19, 534-542.

[10] Palhares, D.M., Marcolino, M.S., Santos, T.M., et al. (2017). Normal Limits of the Electrocardiogram Derived from a Large Database of Brazilian Primary Care $\mathrm{Pa}$ tients. BMC Cardiovascular Disorders, 17, Article No. 152. https://doi.org/10.1186/s12872-017-0572-8

[11] Draper, H.W., Peffer, C.J., Stallmann, F.W., et al. (1964) The Corrected Orthogonal Electrocardiogram and Vectorcardiogram in 510 Normal Men (Frank Lead System). Circulation, 30, 853-864. https://doi.org/10.1161/01.CIR.30.6.853 
[12] Chaudhry, S., Muthurajah, J., Lau, K. and Xiao, H.B. (2019) The Effect of Ageing on the Frontal QRS-T Angle on the 12-Lead ECG. The British Journal of Cardiology, 26, 157-158. http://dx.doi.org/10.5837/bjc.2019.034

[13] Pinto-Filho, M.M., Brant, L.C., Foppa, M., Garcia-Silva, K.B., Mendes de Oliveira, R.A., et al. (2017) Major Electrocardiographic Abnormalities According to the Minnesota Coding System among Brazilian Adults (from the ELSA-Brasil Cohort Study). (ABSTRACT). American Journal of Cardiology, 119, 2081-2087.

https://doi.org/10.1016/j.amjcard.2017.03.043

[14] Prineas, R.J., Le, A., Soliman, E.Z., Zhang, Z., Howard, V.J., Ostchega, Y. and Howard, G. (2012) United States National Prevalence of Electrocardiographic Abnormalities in Black and White Middle-Age (45- to 64-Year) and Older ( $\geq 65$-year) Adults (from the Reasons for Geographic and Racial Differences in Stroke Study). American Journal of Cardiology, 109, 1223-1228.

https://doi.org/10.1016/j.amjcard.2011.11.061

[15] Whang, W., Shimbo, D., Levitan, E.B., et al. (2012) Relations between QRS|T Angle, Cardiac Risk Factors, and Mortality in the Third National Health and Nutrition Examination Survey (NHANES III). The American Journal of Cardiology, 109, 981-987. https://doi.org/10.1016/j.amjcard.2011.11.027

[16] Stinebaugh, B.J., Schloeder, F.X. and Dealba, E. (1965) An Evaluation of the Frontal Plane ORS-T Angle in Normal Adults. Archives of Internal Medicine, 116, 810-812. 